\title{
Effect of reduced expiratory pressure on pharyngeal size during nasal positive airway pressure in patients with sleep apnoea: evaluation by continuous computed tomography
}

\author{
Matthias Gugger, Peter Vock
}

\begin{abstract}
Background This study aimed to determine whether reducing the expiratory pressure during nasal positive airway pressure for reasons of comfort causes a substantial decrease in the upper airway calibre.
\end{abstract}

Methods Eight patients with obstructive sleep apnoea were studied. Continuous computed tomography ( each run lasting 12 seconds) was used to measure minimum and maximum pharyngeal cross sectional areas at the velopharynx and the hypopharynx. Pharyngeal areas were measured while patients were awake and breathing without assistance, during the application of $12 \mathrm{~cm} \mathrm{H}_{2} \mathrm{O}$ continuous positive airway pressure, and during bilevel positive airway pressure with an inspiratory pressure of $12 \mathrm{~cm} \mathrm{H_{2 }} O$ and an expiratory pressure of $6 \mathrm{~cm} \mathrm{H} \mathrm{H}_{2} \mathrm{O}$.

Results Nasal continuous positive airway pressure significantly increased the mean minimum and maximum upper airway areas at both the velopharynx and the hypopharynx compared with normal unassisted breathing. Bi-level positive airway pressure did not show a statistically significant increase in the minimum upper airway area at either level compared with normal unassisted breathing. The minimum areas of the velopharynx and hypopharynx were smaller with bi-level than continuous positive airways pressure in six of eight and eight of eight patients respectively but these were still greater than during unassisted breathing in seven of eight and six of eight patients respectively.

Conclusions Continuous positive airway pressure at $12 \mathrm{~cm} \mathrm{H}_{2} \mathrm{O}$ is more effective in splinting the pharynx open than bilevel positive airway pressure with an inspiratory positive airway pressure of $12 \mathrm{~cm} \mathrm{H}_{2} \mathrm{O}$ and an expiratory pressure of $6 \mathrm{~cm} \mathrm{H}_{2} \mathrm{O}$ in patients with obstructive sleep apnoea during wakefulness, suggesting an important role for expiratory positive airway pressure. The clinical importance of this finding needs to be evaluated during sleep

(Thorax 1992;47:809-813)
Nasal continuous positive airway pressure (CPAP) is an established treatment for obstructive sleep apnoea. ${ }^{12}$ With pressures of $10 \mathrm{~cm} \mathrm{H}_{2} \mathrm{O}$ or higher, however, the resistance felt during expiration and the required tightness of the nose mask can be unpleasant for the patient and may therefore impair treatment compliance. To overcome these difficulties a more sophisticated technique, a bi-level positive airway pressure device (Bi-PAP; Respironics Inc, Monroeville, PA, USA) has been developed that allows separate adjustments of inspiratory and expiratory positive airway pressures.

Numerous studies have investigated the dimensions of the upper airways in awake subjects and discussed their importance with regard to sleep apnoea. ${ }^{3-11}$ Two groups succeeded in obtaining computed tomograms during sleep and found that upper airways were narrower than during wakefulness. ${ }^{12}{ }^{13}$ In a recent review on the mode of action of nasal CPAP, Sullivan and Grunstein stated that 'all the evidence points to its action as a physical pressure splint as the dominant reason for its success' ${ }^{14}$ The results of a study using endoscopic observation and a recent study measuring pharyngeal volume by magnetic resonance imaging provide further evidence that nasal CPAP works mainly by enlarging the pharyngeal size and splinting the airway open. ${ }^{15}{ }^{16} \mathrm{It}$ is not known, however, whether Bi-PAP is as efficient in dilating the upper airway as conventional CPAP or whether the greater comfort of lower expiratory pressures permits a substantial reduction in the upper airway calibre. We used computed tomography to determine the effect of CPAP and Bi-PAP on upper airway calibre in awake patients suffering from obstructive sleep apnoea.

\section{Methods}

SUBJECTS AND SLEEP STUDIES

Eight men (mean (SD) age $53(6 \cdot 7)$ years, mean body mass index $32(5) \mathrm{kg} / \mathrm{m}^{2}$ ) with a diagnosis of obstructive sleep apnoea took part in the study. Overnight polysomnography (mean (SD) apnoea/hypopnoea index 55 (10.3)) was performed between six and 12 months before the study in all patients. Oronasal flow was monitored with thermocouples and thoracoabdominal movement by inductance plethys- 
mography (Respitrace, Respitrace, Ardsley, NY, USA). Sleep was monitored by recording the electroencephalogram (silver cup electrodes, F0 C0 P0 T4 T3), electromyogram (submental and nuchal), and electro-oculogram (four electrodes outside and above the outer canthi). Finger oxygen saturation was monitored with an Ohmeda Biox 3700 oxymeter. All signals were recorded on an 18 channel van Gogh polygraph. Sleep stage was determined by the criteria of Rechtschaffen and Kales. ${ }^{17}$ Any cessation in airflow that lasted longer than 10 seconds was scored as an episode of apnoea. Obstructive apnoea was considered present when an episode of apnoea was associated with inductance plethysmography deflections indicating thoracoabdominal movement. A $>50 \%$ decrease in thoracoabdominal amplitude (shown on the Respitrace) for 10 seconds or longer in the presence of continued airflow was scored as hypopnoea. ${ }^{18}$ Seven patients were having CPAP treatment at home and patient 8 was waiting for his CPAP ventilatory support system to be delivered. The mean (SD) CPAP value of the eight patients was $10 \cdot 8(2 \cdot 8) \mathrm{cm} \mathrm{H}_{2} \mathrm{O}$.

Informed consent was obtained and the investigation was approved by the hospital authority.

\section{POSITIVE AIRWAY PRESSURE DEVICE}

A Bi-PAP S/T-D ventilatory support system (Respironics Inc, Monroeville, PA, USA) was used for CPAP and Bi-PAP. This device allows separate ajustment of inspiratory (IPAP) and expiratory (EPAP) positive airway pressure. In this study the pressure was set at $12 \mathrm{~cm} \mathrm{H}_{2} \mathrm{O}$ for CPAP. IPAP was set at $12 \mathrm{~cm} \mathrm{H}_{2} \mathrm{O}$ and EPAP at $6 \mathrm{~cm} \mathrm{H}_{2} \mathrm{O}$ during $\mathrm{Bi}-\mathrm{PAP}$ application. The spontaneous mode was used for Bi-PAP. The pressures were calibrated by a water manometer. The patients used their own face masks (Respironics Inc) to ensure a good fit and comfort. Practice runs were performed immediately before computed tomography.

\section{COMPUTED TOMOGRAPHY}

A third generation scanner with continuous rotation capabilities (Somatom Plus, Siemens Company, Germany) was used. Computed tomography of the upper airways was performed with the head in a neutral, supine position and the subjects awake. Head position was maintained constant by a harness. A lateral view (topographic scout view) was taken to determine the scanning levels. Two parallel sections perpendicular to the posterior pharyngeal wall were selected, one at the level of the soft palate (velopharynx) and the other above the tip of the epiglottis (hypopharynx). The slice thickness was $1 \mathrm{~mm}$, the tube current $150 \mathrm{~mA}$. All computed tomography was performed during quiet tidal breathing without breathholding. ${ }^{79}$ The patients were instructed to keep their mouth closed, not to move at any time during the examination, and not to swallow when the scans were being performed. Patients were reminded of these instructions before each scanning run.

The computed tomography computer was always started at the end of an inspiration, determined by observation. The time gap between starting the computer and the actual acquisition of an image sequence was three seconds. During each run (image acquisition sequence), computed tomography projections (raw data) were continuously acquired for 12 seconds and included at least two full respiratory cycles.

Since the projections obtained over 0.7 seconds (corresponding to 0.7 seconds of a full rotation) were the minimum required to reconstruct an image, 23 overlapping 0.7 second images were reconstructed at intervals of 0.5 seconds from the raw data of a single sequence. Hard copies were taken at a window width of $600 \mathrm{HU}$ and a level of $+40 \mathrm{HU}$.

The cross sectional areas of the upper airways were measured semiautomatically using experimental software designed for quantitative densitometric pulmonary studies. ${ }^{1920} \mathrm{~A}$ starting point inside the lumen of the upper airway was indicated manually (with the cursor) on the monitor. Including adjacent pixels of densities between -100 and $-1024 \mathrm{HU}$, an automatic and precise tracing of the airway circumference (fig 1) and determination of the airway area was then performed by the computer. The accuracy of airway calibre determination by computed tomography had been verified in an earlier study. ${ }^{21}$ If necessary, user interaction served to verify inclusion of only the functional air column behind the soft palate-that is, to exclude the non-functional airway between the tongue and the soft palate. In the lower hypopharyngeal airway, the area occupied by the tip of the epiglottis was included in the cross sectional measurements in cases where it became visible.

From each single computed tomography sequence (each of 23 images) the images with the minimum and maximum cross sectional area were used for comparisons.

\section{PROTOCOL}

In each patient a total of six computed tomography sequences were obtained during

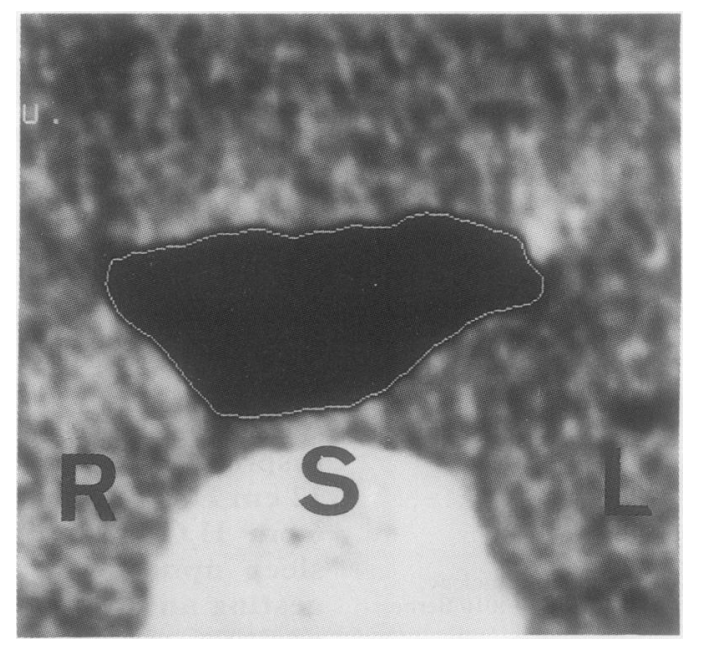

Figure 1 Computed tomogram of the velopharynx during bi-level positive airway pressure. The circumference of the airway is outlined by automatic electronic cursor (see Methods). $R=$ right; $L=$ left; $S=$ spine. 
Figure 2 Changes in the cross sectional area of the velopharynx in patient

No 4 over three 12 second sequences during

spontaneous breathing

(circles), constant positive airway pressure (CPAP) (squares) and bi-level

positive airway pressure

(Bi-PAP) (triangles). computed tomography

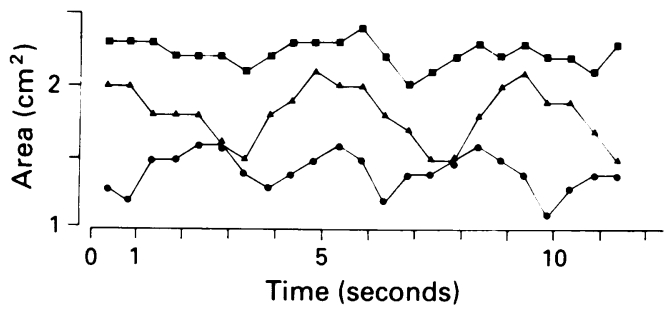

quiet tidal breathing. Three of the six sequences were obtained at the velopharynx and three at the hypopharynx. Twenty three images per sequence were obtained during each of the six 12 second periods of continuous scanning in each patient $(6 \times 23$ images per patient $)$.

Firstly, the three computed tomography sequences at the velopharynx were obtained. Sequence one was obtained while the patients wore the nose mask but were not being subjected to PAP. Sequence two was obtained during $\mathrm{CPAP}$ and sequence three during Bi-PAP via a nose mask.

Secondly, the three sequences at the hypopharynx were obtained in the same order.

The patients were on CPAP or Bi-PAP respectively for 2 minutes before each scan with PAP.

The patients could not be blinded to the three procedures and therefore a fixed order of administration of no PAP, CPAP, and Bi-PAP was chosen.

\section{STATISTICAL ANALYSIS}

One way analysis of variance and Duncan's multiple range post hoc test were used to compare pharyngeal areas. The significance level was taken to be $p<0.05$. Mean (SD) values are given.

\footnotetext{
Figure 3 Individual minimum and maximum upper airway cross sectional areas of the velopharynx.

$S=$ spontaneous breathing without positive airway pressure, $C=$ constant positive airway pressure, $B I=b i$-level positive airway pressure. Only significant $p$ values are shown.
}

\section{Results}

Figure 2 shows the effects of both CPAP and BiPAP on upper airway dimensions and their periodic variability in one patient. The tracings show the changes in cross sectional areas at the velopharyngeal level registered during three 12 second scanning sequences.

The effects of nasal CPAP and Bi-PAP on the minimum and maximum cross sectional areas of both velopharynx and the hypopharynx are shown in figures 3 and 4, and in table 1 . Three findings appear noteworthy. Firstly, in line with previous studies a CPAP of $12 \mathrm{~cm} \mathrm{H}_{2} \mathrm{O}$ considerably and significantly increased the minimum and maximum cross sectional areas of both the velopharynx and the hypopharynx. Secondly, compared with the data obtained during unassisted breathing the effects of $\mathrm{Bi}$ PAP were less consistent: only the increase of the maximum area at the velopharynx reached statistical significance. At the hypopharynx, however, three out of eight patients did not show any appreciable airway widening. Lastly, between the CPAP and Bi-PAP applications there was a conspicuous and highly significant difference in the mean minimal cross sectional area of the hypopharynx.

\section{Discussion}

The most important finding of this study is that dilatation of the upper airway is reduced during Bi-PAP breathing at the chosen pressure settings, as reflected by the insignificant increases in the crucial minimum cross sectional areas at both the velopharynx and hypopharynx. The

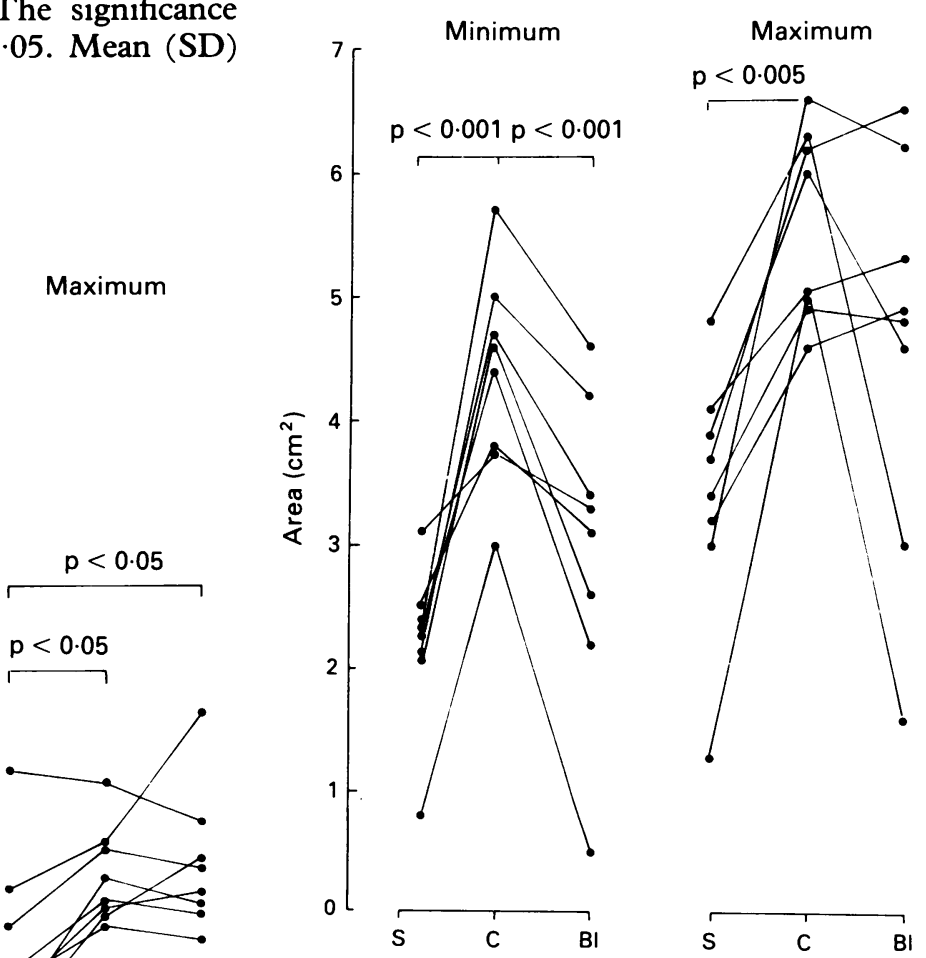

Figure 4 Individual minimum and maximum upper airway cross sectional areas of the hypopharynx. $S=$ spontaneous breathing without positive airway pressure application, $C=$ constant positive airway pressure, $B I=b i$-level positive airway pressure. Only significant $p$ values are shown. 
Mean cross sectional upper airway areas $\left(\mathrm{cm}^{2}\right)$

\begin{tabular}{|c|c|c|c|c|c|c|c|c|c|c|c|c|}
\hline & \multicolumn{6}{|c|}{ Velopharynx } & \multicolumn{6}{|c|}{ Hypopharynx } \\
\hline & \multicolumn{2}{|c|}{ Spontaneous } & \multicolumn{2}{|c|}{$C P A P$} & \multicolumn{2}{|c|}{$B i-P A P$} & \multicolumn{2}{|c|}{ Spontaneous } & \multicolumn{2}{|l|}{$C P A P$} & \multicolumn{2}{|c|}{$B i-P A P$} \\
\hline & Min & $\operatorname{Max}$ & Min & $\operatorname{Max}$ & Min & $\operatorname{Max}$ & Min & $\operatorname{Max}$ & Min & $\operatorname{Max}$ & Min & $\operatorname{Max}$ \\
\hline $\begin{array}{l}\text { Mean } \\
\text { (SD) }\end{array}$ & $\begin{array}{c}0.83 \\
(0.58)\end{array}$ & $\begin{array}{c}1.40 \\
(0.73)\end{array}$ & $\begin{array}{c}1.44 \\
(0.40)\end{array}$ & $\begin{array}{c}2 \cdot 04 \\
(0 \cdot 40)\end{array}$ & $\begin{array}{c}1.24 \\
(0.54)\end{array}$ & $\begin{array}{c}2 \cdot 14 \\
(0 \cdot 60)\end{array}$ & $\begin{array}{c}2 \cdot 20 \\
(0 \cdot 65)\end{array}$ & $\begin{array}{c}3.43 \\
(1.03)\end{array}$ & $\begin{array}{c}4 \cdot 38 \\
(0 \cdot 83)\end{array}$ & $\begin{array}{c}5 \cdot 56 \\
(0 \cdot 77)\end{array}$ & $\begin{array}{c}2.99 \\
(1.27)\end{array}$ & $\begin{array}{c}4.61 \\
(1.62)\end{array}$ \\
\hline
\end{tabular}

$\mathrm{CPAP}=$ constant positive airway pressure $\mathrm{Bi}-\mathrm{PAP}=$ bi-level positive airway pressure

comparative data obtained in the same patients during CPAP application, which are consistent with the results observed in previous studies, ${ }^{7822}$ confirm that the relative lack of effect of $\mathrm{Bi}$-PAP is not a consequence of patient selection or of technical problems.

Several factors in the current study must be considered. Firstly, because ultrafast cine computed tomography was not available we were not able to monitor precisely the dimensional changes of the upper airways within a single respiratory cycle. Instead, a modern general purpose scanner was used with continuous rotation and scanning, typically at a rate of one rotation per scan. We chose $700 \mathrm{~ms}$ scans, and by reconstructing them every $500 \mathrm{~ms}$ obtained some temporal overlap. Hence, it is possible that some short-lasting volume changes of the pharynx have been missed. This disadvantage, however, is probably outweighed by the continuous data acquisition over a longer period of time. An additional technical problem pertains

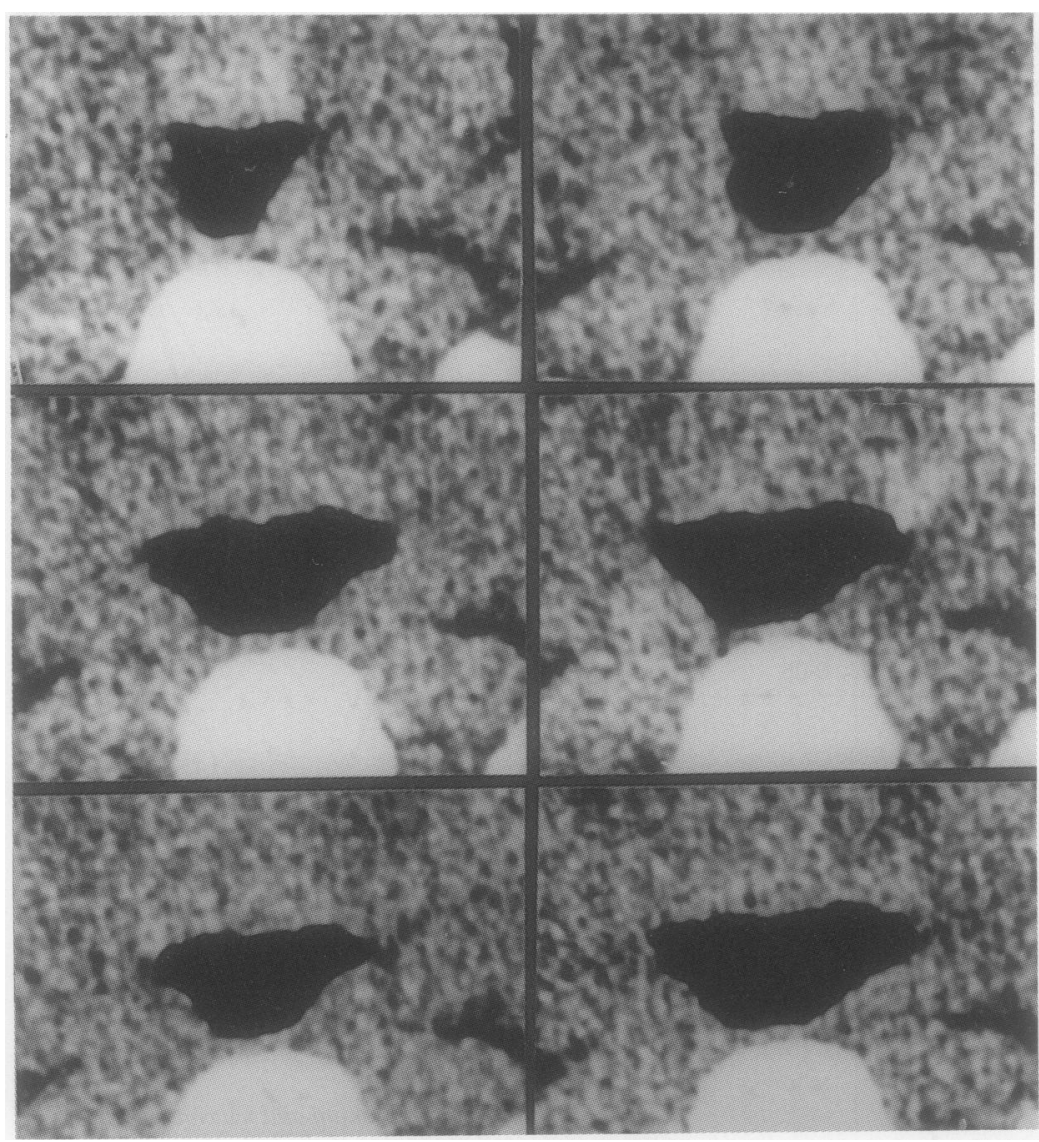

Figure 5 Computed tomograms showing minimum (left) and maximum (right) airway area at the velopharynx during spontaneous breathing without positive airway pressure application (top), with constant positive airway pressure (middle) and bi-level positive airway pressure (bottom) application. For orientation see figure 1. to the determination of the cross sectional areas of the pharynx. Since the drawing of airway circumferences and the calculation of cross sectional areas are by computer, a userdependent bias can be excluded. Previous evaluation of the method used in this study is reassuring and our data compare favourably with those of others. ${ }^{51219-21}$

Secondly, can data obtained during wakefulness be extrapolated to sleeping patients. Making measurements during sleep would be most accurate but this is difficult to achieve with today's technology ${ }^{3-11}$ and thus only scanty computed tomography data during sleep are available. ${ }^{12}{ }^{13}$ Evidently, the effect of any PAPapplication as therapy for sleep apnoea must eventually be ascertained by polysomnographical studies. There is, however, considerable evidence that the finding of a splinting effect of PAP-application during wakefulness has some predictive power to choose an adequate modality to treat patients with sleep apnoea. ${ }^{141623}$

Finally, one might argue that the insufficient effect of Bi-PAP observed in this study was predictable as the average pressure over a respiratory cycle was lower (about $9 \mathrm{~cm} \mathrm{H}_{2} \mathrm{O}$ ) than during CPAP $\left(12 \mathrm{~cm} \mathrm{H}_{2} \mathrm{O}\right)$. Indeed, it is possible that by increasing the $\mathrm{Bi}-\mathrm{PAP}$ to an average pressure of $12 \mathrm{~cm} \mathrm{H}_{2} \mathrm{O}$, a significant effect on upper airway dimensions may be achieved. This study could not check this by a dose-response relation with $\mathrm{Bi}-\mathrm{PAP}$, but recent studies indicate that the problem is complex. Kuna et $a l^{8}$ have shown an approximately linear relation between the CPAP level and upper airway calibre. On the assumption that the average pressure is the most relevant parameter, a more noticeable effect of Bi-PAP should have been detectable in the present study. The relatively small number of patients studied may be responsible for the fact that differences in upper airway size between $\mathrm{Bi}$ PAP and both CPAP and no PAP were not clearly seen. However, by inference from a careful polysomnographical study it appears that the expiratory pressure is of considerable importance in that it may influence the effect of inspiratory pressure. ${ }^{24}$

It has been shown that patients with obstructive sleep apnoea have a smaller pharyngeal area $^{41122}$ and that longstanding CPAP treatment increases the pharyngeal area during breathing without PAP compared with pretreatment measurements. ${ }^{25}$ Furthermore, it has been shown that pharyngeal transverse diameters are smaller in patients than in healthy subjects. ${ }^{26}$ In this study, visual inspection 
of the computed tomograms showed clearly that the increase in pharyngeal area with CPAP or Bi-PAP was mainly the consequence of an increased transverse diameter in all subjects, illustrated in one patient in figure 5. Thus, CPAP or Bi-PAP seem to increase the size of the upper airway by restoring its physiological shape.

In conclusion, Bi-PAP with an inspiratory pressure of $12 \mathrm{~cm} \mathrm{H}_{2} \mathrm{O}$ an an expiratory pressure of $6 \mathrm{~cm} \mathrm{H}_{2} \mathrm{O}$ seems to be much less effective in splinting the upper airway open than a CPAP of $12 \mathrm{~cm} \mathrm{H}_{2} \mathrm{O}$. This finding in awake patients with obstructive sleep apnoea is of physiological interest but further sleep studies are required to determine its clinical relevance.

1 Sullivan CE, Issa FG, Berthon-Jones M, Eves L. Reversal of obstructive sleep apnoea by continuous positive airway pressure applied through the nares. Lancet 1981;i:862-5.

2 Sullivan CE, Issa FG, Berthon-Jones M, McCauley V, Costas L. Home treatment of obstructive sleep apnoea with continuous positive airway pressure applied through a nose-mask. Bull Eur Physiopathol Respir 1984;20:49-54.

3 Haponik EF, Smith PL, Bohlman ME, Allen RP, Goldman SM, Bleecker ER. Computerized tomography in obstructive sleep apnea. Correlation of airway size with physiology during sleep and wakefulness. Am Rev Respir Dis 1983;127:221-6.

4 Suratt PM, Dee P, Atkinson RL, Armstrong P, Wilhoit SC. Fluoroscopic and computed tomographic features of the pharyngeal airway in obstructive sleep apnea. $A m R e v$ Respir Dis 1983;127:487-92.

5 Bohlman ME, Haponik EF, Smith PL, Allen RP, Bleecker ER, Goldman SM. CT demonstration of pharyngeal narrowing in adult obstructive sleep apnea. $A m J$ Roentgenol 1983;140:543-48.

6 Stauffer JL, Zwillich CW, Cadieux RJ, Bixler EO, Kales A Varano LA, White DP. Pharyngeal size and resistance in obstructive sleep apnea. Am Rev Respir Dis 1987;136: 623-7.

7 Brown IB, McClean PA, Boucher R, Zamel N, Hoffstein V. Changes in pharyngeal cross-sectional area with posture and application of continuous positive airway pressure in patients with obstructive sleep apnea. Am Rev Respir Dis 1987;136:628-32.

8 Kuna ST, Bedi DG, Ryckman C. Effect of nasal airway positive pressure on upper airway size and configuration. Am Rev Respir Dis 1988;138:969-75.

9 Standord W, Galvin J, Rooholamini M. Effect of awake tidal breathing, swallowing, nasal breathing, oral breathing and the Müller and Valsalva maneuvers on the dimensions of the upper airway. Evaluation by ultrafast computerized tomography. Chest 1988;94:149-54.
10 Shepard JW, Thawley SE. Evaluation of the upper airway by computerized tomography in patients undergoing uvulopalatopharyngoplasty for obstructive sleep apnea. Am Rev Respir Dis 1989;140:711-6.

11 Galvin JR, Rooholamini SA, Stanford W. Obstructive sleep apnea: diagnosis with ultrafast CT. Radiology 1989;171: 775-8.

12 Stein MG, Gamsu G, deGeer G, Golden JA, Crumley RL, Webb WR. Cine-CT in obstructive sleep apnea. Am J Roentgenol 1987;148:1069-74.

13 Horner L, Shea SA, McIvor J, Guz A. Pharyngeal size and shape during wakefulness and sleep in patients with obstructive sleep apnoea. Quart J Med 1989;72:719-35.

14 Sullivan CE, Grunstein RR. Continuous positive airways pressure in sleep-disordered breathing: nasal CPAP: mode of action. In: Kryger MH, Roth T, Dement WC, eds. Principles and practice of sleep medicine. 1st ed. Philadelphia: WB Saunders, 1989:559-70.

15 Popper RA, Leidinger MJ, Williams AJ. Endoscopic observations of the pharyngeal airway during treatment of obstructive sleep apnea with nasal continuous positive airway pressure-a pneumatic splint. West J Med 1986; 144:83-5.

16 Abbey NC, Block AJ, Green D, Mancuso A, Hellard DW. Measurement of pharyngeal volume by digitized magnetic resonance imaging. Effect of nasal continuous positive airway pressure. Am Rev Respir Dis 1989;140:717-23.

17 Rechtschaffen A, Kales A. A manual of standardized terminology, techniques and scoring systems for sleep stages of human subjects. Washington DC: National Institutes of Health, 1968:Publ No 204.

18 Gould GA, Whyte KF, Rhind GB, Airlie MAA, Catterall JR, Shapiro CM, Douglas NJ. The sleep hypopnea syndrome. Am Rev Respir Dis 1988;137:895-98.

19 Kalender WA, Rienmüller R, Seissler W, Behr J, Welke M, Fichte $\mathrm{H}$. Measurement of pulmonary parenchymal attenuation: use of spirometric gating with quantitative CT. Radiology 1990;175:265-8.

20 Kalender $\mathbb{W}$, Rienmüller $R$, Welke $M$. Algorithm for automated evaluation of high-resolution CT images of the lung. Radiology 1988;169(P):116.

21 Vock P, Spiegel T, Fram EK, Effmann EL. CT assessment of the adult intrathoracic cross section of the trachea. J Comput Assist Tomogr 1984;8:1076-82.

22 Shepard JW, Garrison M, Vas W. Upper airway distensibility and collapsibility in patients with obstructive sleep apnea. Chest 1990;98:84-91.

23 Rapoport DM, Garay SM, Goldring RM. Nasal CPAP in obstructive sleep apnea: mechanisms of action. Bull Eur Physiopathol Respir 1983;19:616-20.

24 Sanders MH, Kern N. Obstructive sleep apnea treated by independently adjusted inspiratory and expiratory positive airway pressure via nasal mask. Physiologic and clinical implications. Chest 1990;98:317-24.

25 Ryan CF, Lowe AA, Li D, Fleetham JA. Magnetic resonance imaging of the upper airway in obstructive sleep apnea before and after nasal CPAP therapy. Am Rev Respir Dis 1991;144:939-44.

26 Rodenstein DO, Dooms G, Thomas Y, Liistro G, Stanescu DC, Culee $\mathrm{C}$, et al. Pharyngeal shape and dimensions in healthy subjects, snorers, and patients with obstructive sleep apnoea. Thorax 1990;45:722-7. 